\title{
Understanding the determinants of novel technology adoption among teachers: the case of 3D printing
}

\author{
Patrick Holzmann $^{1}$ (D) Erich J. Schwarz ${ }^{1}$. David B. Audretsch ${ }^{2}$ \\ Published online: 14 September 2018 \\ (c) The Author(s) 2018
}

\begin{abstract}
3D printing consists of novel technologies that raised high expectations about their future impact on economy and society. However, despite major efforts of manufacturers and governments to promote the technology, the adoption rate is still low. Among others, the absence of appropriate technology education is considered a major hurdle for adoption. The main goal of this paper is to investigate the behavioral intention of high school teachers to use these novel technologies in class. We propose applying the unified theory of acceptance and use of technology by integrating anxiety and attitude toward using technology. Data from 103 high school teachers is utilized to empirically validate the conceptual model. The results show that performance expectancy, facilitating conditions, anxiety, and attitude toward using technology significantly affect the adoption of novel technology. Contrary to expectations, effort expectancy and social influence do not affect the behavioral intention. Thus, the study adds to prior knowledge by underlining the need for further investigation of the relevance of anxiety and attitude toward using a novel technology in individual adoption processes.
\end{abstract}

Keywords Technology adoption · Technology acceptance $\cdot$ Novel technology $\cdot$ Behavioral intention $\cdot \mathrm{UTAUT} \cdot 3 \mathrm{D}$ printing

JEL Classification $\mathrm{O} 30 \cdot \mathrm{O} 33 \cdot \mathrm{M} 10 \cdot \mathrm{M} 13 \cdot \mathrm{I} 20 \cdot \mathrm{C} 12$

\section{Introduction}

3D printers produce three-dimensional objects by adding material layer upon layer (Kwak et al. 2017). These novel technologies distinguish themselves significantly from conventional production processes. Due to their novelty, 3D printing technologies have generated high, yet sometimes divergent, expectations (Rayna and Striukova 2016) about their future

Patrick Holzmann

patrick.holzmann@aau.at

1 Department of Innovation Management and Entrepreneurship, Alpen-Adria University Klagenfurt, Universitaetsstrasse 65-67, 9020 Klagenfurt, Austria

2 School of Public and Environmental Affairs, Indiana University, 1315 E. Tenth Street, Bloomington, IN 47405-1701, USA 
effects on the economy, policy, and society (Gartner et al. 2015; Jiang et al. 2017; Xu et al. 2017). For instance, because of their novel functionality, the technology is able to alter traditional manufacturing processes significantly. 3D printing can facilitate cost-effective production even at small scales and increase production speed of customized products. Further, 3D printers can produce complex parts in one piece, instead of the normal separate casting of various parts. This reduction in the assembly of components allows reducing costs of manufacturing (Holmström et al. 2010; Berman 2012). As a result, these novel technologies introduce previously unattainable business opportunities (Holzmann et al. 2017). In addition, 3D printing can positively affect environmentally friendly production, because it can reduce the amount of input material needed and the amount of waste produced (Holmström et al. 2010; Berman 2012). Further, 3D printing enables producing fully individualized products. One poignant example is customized healthcare products that improve population health and quality of life (Huang et al. 2013).

Several countries, such as the U.S. and UK, have invested heavily in order to encourage the adoption of these novel technologies (Schniederjans 2017). Manufacturers work on technological improvements and adequate business models (Holzmann et al. 2015) to accelerate technology diffusion. However, despite these efforts, the adoption process of these technologies remains slow. Diffusion of new production techniques, such as 3D printing, is typically measured by the share of output that is produced with the technology (Comin et al. 2008). Studies highlight that the market share of 3D printing in the manufacturing market is less than two per cent (Wohlers and Caffrey 2014). At least anecdotal evidence suggests that companies still struggle to incorporate the technology in their production processes (Yeh and Chen 2018). Reasons for this are manifold, but have not yet been sufficiently analyzed (e.g. Schniederjans 2017; Yeh and Chen 2018). Research so far has primarily focused on ecnomocial issues to explain the phenomenon. For instance, the higher marginal costs of manufacturing compared to traditional manufacturing processes (Despeisse et al. 2017).

We propose that besides the economical issues (Albors et al. 2006; Ozusaglam et al. 2017) there are also knowledge and skills related issues that limit adoption. In order to use this novel technology to its full potential, specific knowledge and skills are required (Weller et al. 2015). For instance, designers need to be aware of the technologies requirements and principles. This specific knowledge is a prerequisite in order to design and produce complex parts in one piece. Thus, 3D printing opens up novel possibilities in the design process. However, it also requires a fundamentally different logic of thinking. The implementation of the technology demands extensive adaptions not only in the production but in the entire value creation process. Companies that contemplate about adopting the technology need to be aware that they require employees that possess the requisite skills to operate 3D printers. This means there is a pressing need for specific education.

At the global scale, numerous universities (e.g. MIT) have already integrated 3D printing classes in their curricula. In Austria, some universities (e.g. AAU Klagenfurt, TU Graz) run $3 \mathrm{D}$ printing labs. Comprehensive $3 \mathrm{D}$ printing education at the high school level is crucial to enable the timely development of required skillsets, yet 3D printing is still novel at the high school level. This study addresses the behavioral intention of high school teachers to adopt novel technology. This study builds upon the Unified Theory of Acceptance and Use of Technology (UTAUT) to investigate the behavioral intention of teachers to use novel technology. Our model incorporates attitudes and perceived facilitating conditions. The main goal of our study is to determine which dimensions affect the adoption of novel technology by high school teachers. The paper is organized as follows. Section 2 presents the theoretical framework and literature review. Section 3 introduces our model to measure 
the behavioral intention to use 3D printing. Section 4 presents the results of our empirical study. Finally, Sect. 5 provides conclusions and suggests opportunities for future research.

\section{Theoretical framework}

\subsection{Technology adoption}

Scholars have proposed several theoretical models that aim to predict the acceptance and usage of technology. Venkatesh et al. (2003) conducted an empirical study to review the existing technology adoption literature. The aim of their study was to develop a more complete IT acceptance model. Thus, they compared the social cognitive theory (SCT) (Bandura 1986), the theory of reasoned action (TRA) (Sheppard et al. 1988), the technology adoption model (TAM) (Davis 1989; Davis et al. 1989), the theory of planned behavior (TPB) (Ajzen 1991), the model of PC utilization (MPCU) (Thompson et al. 1991), and the innovation diffusion theory (IDT) (Moore and Benbasat 1991). Based on the results of their investigation, Venkatesh et al. developed the Unified Theory of Acceptance and Use of Technology (UTAUT). The empirical results demonstrate that UTAUT is able to predict technology acceptance better than the existing models. The UTAUT is primarily based on the TPB. According to the TPB behavioral intention (BI) precedes a specific behavior, for instance, the usage of technology (Venkatesh et al. 2003). The role of intention as a predictor of behavior is well established in the literature (e.g. Sheppard et al. 1988; Taylor and Todd 1995). According to Verdegem and De Marez (2011), BI can be considered as the nearest proxy for actual use behavior. The BI is further determined by attitude, norm, and the perception of control over the behavior. The UTAUT model proposes three direct predictors: performance expectancy (PE), effort expectancy (EE), and social influence (SI) of an individual's BI to use technology (Venkatesh et al. 2003).

\subsection{Novel technology adoption in education}

The previous studies have generally analyzed the adoption and use of different technologies. However, the number of studies that focus on novel technology adoption is small. As a result, knowledge on novel technology adoption in general is still insufficient. Hence, there is also a lack of studies that investigate novel technology adoption in education contexts. Sumak and Sorgo (2016) reviewed the literature on electronic learning and concluded that the overall number of adoption studies remains small and insufficient. In addition, they demonstrated that these studies indicate different results concerning the determinants that lead to technology adoption in education. Further, Sumak and Sorgo (2016) underline the need for research on the acceptance and use of novel technologies in this context. Previous research has primarily examined the acceptance and use of technologies with a relatively low degree of novelty. To the best of our knowledge, there is no empirical study with the goal of explicitly predicting the adoption by high school teachers of novel technologies such as 3D printing technology. The present study intends to fill this research gap. 


\subsection{Model of behavioral intention to use 3D printing}

In this study, we chose the UTAUT as the basis framework to develop our research model. Based on previous research, we have developed a model for investigating the behavioral intention of teachers to use novel technology. Our research model incorporates both personal and perceived environment-related influence factors. Specifically, the proposed model focuses on six constructs to predict the behavioral intention to use 3D printing. These six constructs are PE, EE, SI, anxiety (ANX), attitude toward using technology (ATUT), and the perception of facilitating conditions (FC) (Fig. 1). We integrate ANX as a predictor in our model, because of the technology's novelty. High levels of technological novelty are often accompanied with complexity and uncertainty. With regard to the novelty of the technology and the divergent opinions on its potential, ANX becomes more important in an individual's adoption decision. We also integrate ATUT in our model because of the technology's novelty. Individuals who currently adopt the technology can be considered as early adopters. With regard to the technology's novelty and currently unknown potential, an individual's ATUT becomes more important. Finally, we investigate the effect of FC on BI. We assume that supporting conditions are of paramount importance, especially for novel technology. Thus, we integrate ANX, ATUT, and FC as predictors in our research model.

\subsubsection{Performance expectancy (PE)}

$\mathrm{PE}$ is defined as the degree to which an individual believes that using the technology will improve the job performance (Venkatesh et al. 2003). According to Sumak and

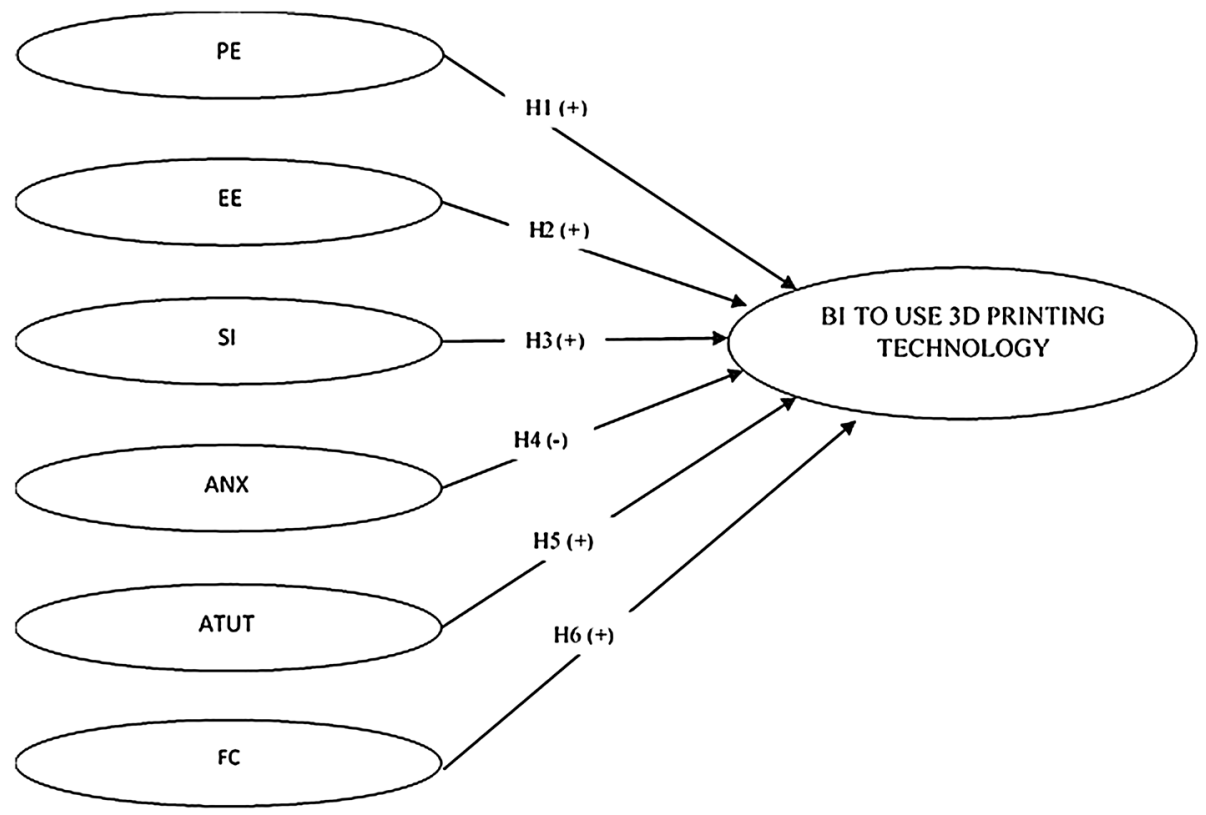

Fig. 1 Model of intention to use 3D printing technology 
Sorgo (2016), PE is most often a significant determinant of teachers' BI to use innovative technology. Macedo (2017) also reports strong effects of PE on BI. In our study, PE is demonstrated by the belief of teachers that using 3D printing technology will contribute to their teaching performance. We propose the following hypothesis.

H1 High levels of PE positively affect teachers' BI to use 3D printing technology.

\subsubsection{Effort expectancy (EE)}

EE is defined as the degree of ease that an individual associates with using the technology (Venkatesh et al. 2003). However, the empirical results for EE are quite indifferent. According to Sumak and Sorgo (2016), almost half of the existing studies on teacher intention and use of e-learning technology have not found a significant relationship between EE and BI. In our study, EE represents the belief about the ease of using 3D printing technology by teachers. The construct reflects the extent to which teachers feel comfortable using 3D printers. To put it differently, EE proposes to measure the individual's perception of the level of effort required to use 3D printing technology. We assume that the higher the perceived EE (ease of technology use, convenience), the more likely that a teacher will intend to adopt 3D printing technology. We propose the following hypothesis.

H2 High levels of EE positively affect teachers' BI to use 3D printing technology.

\subsubsection{Social influence $(\mathrm{SI})$}

SI is defined as the degree to which an individual perceives that important others believe that the technology should be used (Venkatesh et al. 2003). It is represented as a subjective norm in TRA, TAM, and TPB (Macedo 2017). The literature has found heterogeneous results for SI. While, for instance, Oh and Yoon (2014) found a strong path between SI and BI, the study of Magsamen-Conrad et al. (2015) could not report significant evidence of SI affecting BI. In our study, SI relates to the belief of teachers about how other important people (for instance principals, colleagues, close relatives, friends) believe in their use of 3D printing technology. The belief depends on the subjective norm, image, and social factors (Kabra et al. 2017). We propose the following hypothesis.

H3 High levels of SI positively affect teachers' BI to use 3D printing technology.

\subsubsection{Anxiety (ANX)}

UTAUT does not include the ANX construct as a direct predictor of BI. However, anxiety is a significant driver of intention in SCT. Further, previous research (Venkatesh 2000) has shown that ANX is a conceptually and empirically distinct construct. Hoque and Sorwar (2017) indicate that ANX is a significant driver of BI. In addition, Redmann and Kotrlik (2004) report that a low level of ANX increases teacher technology adoption. ANX is represented as a negative emotional response. It describes an individual's perceived apprehension or discomfort related to using a technology (Meuter et al. 2003). 
In our study, ANX represents the perceived level of apprehension that teachers relate to using $3 \mathrm{D}$ printing technology. We propose the following hypothesis.

H4 High levels of ANX negatively affect teachers' BI to use 3D printing technology.

\subsubsection{Attitude toward using technology (ATUT)}

ATUT is defined as the degree of overall affective reaction of an individual to using the technology (Venkatesh et al. 2003). It relates to an individual's thinking and feelings about the usage of technology (Sumak and Sorgo 2016). According to Venkatesh et al. (2003), ATUT can significantly affect BI. Further, in their revised version UTAUT2 (Venkatesh et al. 2012), they integrate hedonic motivation into their model to explain technology adoption in consumer contexts. Hedonic motivation is defined as the fun and pleasure that an individual derives from the use of the technology. Thus, the concept is quite similar to the ATUT. Because of the context of our study we decided to use ATUT and not hedonic motivation. We include ATUT in our model due to the novelty of 3D printing technology. In our study, ATUT relates to the liking, enjoyment, and fun that teachers associate with the use of 3D printing technology. We propose the following hypothesis.

H5 High levels of ATUT positively affect teachers' BI to use 3D printing technology.

\subsubsection{Facilitating conditions (FC)}

FC are defined as the degree to which an individual believes that there is a supporting organizational and technical infrastructure that helps to use the technology (Venkatesh et al. 2003). In the original version of UTAUT (Venkatesh et al. 2003) FC were theorized only as a driver of actual use behavior. In their revised version UTAUT2 (Venkatesh et al. 2012) FC were also theorized as a driver of behavioral intention. There is also empirical evidence that FC are a strong predictor for BI (e.g. Taiwo and Downe 2013; Yi et al. 2006). Macedo (2017) even demonstrates that for older adults, FC are the second most important predictor of $\mathrm{BI}$, behind $\mathrm{PE}$. The use of 3D printing technology requires specific skills that differ from traditional manufacturing processes, resources, and infrastructure. Thus, it is reasonable that teachers are more willing to adopt 3D printing if they have access to expertise, specific training, and infrastructure. In our study, we assume that teachers' belief about the existence of necessary support to use 3D printing technology positively affects their intention to use $3 \mathrm{D}$ printing. We propose the following hypothesis.

H6 Favorably perceived FC positively affect teachers' BI to use 3D printing technology. 


\section{Empirical study}

\subsection{Study setting}

In order to test our hypotheses, we conducted an empirical study to assess how attitudes and perceived facilitating conditions affect teachers' behavioral intention to accept and adopt novel technology. To this end, we set up a project called "SmartLab goes to school". We were looking for innovative ideas for using 3D printing in high schools; the most innovative ideas could win a $3 \mathrm{D}$ printer for classroom use. Besides a few secondary technical vocational colleges, the majority of high schools do not have $3 \mathrm{D}$ printers yet. The topic was formulated in a sufficiently broad way in order to stimulate a potentially wide range of ideas.

In December 2016, we conducted a kick-off event to present the project. We invited all high schools of an Austrian region to participate in the event. In 2016, there were a total 2876 high school teachers in this region. Women outnumber men. There were 1662 female teachers $(57.8 \%)$ and 1214 male teachers (42.2\%). Finally, 25 teachers participated. These teachers received information about the project and filled out the questionnaire at the event. After the kick-off we contacted the high school principals via mail and asked to distribute the questionnaire among the teachers. The teachers received exactly the same information as those who joined the event. 80 respondents returned the questionnaire.

\subsection{Sample and methodology}

In total, 105 teachers handed in the questionnaire. We excluded all cases with more than ten per cent of missing data. Thus, the sample size was reduced to 103 cases. Our sample consists of 37 (35.9\%) female and $66(64.1 \%)$ male teachers. On average the teachers are 45.9 years old $(\mathrm{SD}=9.6)$. The youngest teacher is 26 years old and the oldest is 64 years old. The respondents have 17.1 years of teaching experience $(\mathrm{SD}=10.4) .24$ teachers $(23.3 \%)$ are employed at academic secondary schools (AHS), 49 teachers $(47.6 \%)$ work at secondary colleges of business administration (HAK), and 30 teachers $(29.1 \%)$ are employed at higher federal technical colleges (HTL). 57 teachers (55.3\%) in our sample are teaching academic or business subjects. 46 teachers $(44.7 \%)$ teach technical subjects. The majority $(89.3 \%)$ of the teachers have full-time positions. 11 teachers $(10.7 \%)$ are employed part-time. $70(68 \%)$ teachers had different jobs before they became teachers. 33 (32\%) teachers in our sample have been teachers for their entire career. 84 teachers $(81.6 \%)$ stated that they have experienced 3D printing already. 19 teachers $(18.4 \%)$ have no experience with the technology.

We applied independent sample $T$ test and ANOVA to test for significant differences in the mean scale values. We found significant group mean differences concerning the three items of behavioral intention to use 3D printing technology between the early adopters and the early majority $(\rho$ value $<0.001)$. There are no significant differences between the three school types (ANOVA). Further, teachers of technical subjects have stronger intentions to use $3 \mathrm{D}$ printing technology than teachers who teach academic or business education subjects $(\rho$ value $<0.05)$. There are no statistically significant differences between female and male teachers intention to use 3D printing technology $(\rho$ value $=0.270)$. Finally, teachers, who have no 3D printing experience have stronger intentions to use $3 \mathrm{D}$ printing ( $\rho$ value $<0.001$ ) (Table 1). 
Table 1 Sample descriptive

\begin{tabular}{llll}
\hline & $\begin{array}{l}\text { Intention to use 3D } \\
\text { printing in the next } \\
6 \text { months? } \\
\text { M (SD) }\end{array}$ & $\begin{array}{l}\text { Prediction to use 3D } \\
\text { printing in the next } \\
6 \text { months? }\end{array}$ & $\begin{array}{l}\text { Plan to use 3D printing } \\
\text { in the next 6 months? }\end{array}$ \\
& M (SD) & M (SD) \\
\hline Early adopter & $6.58(0.83)$ & $6.35(1.30)$ & $6.55(0.96)$ \\
Early majority & $4.28(2.36)$ & $4.18(2.35)$ & $4.33(2.44)$ \\
AHS & $5.25(2.15)$ & $4.91(2.28)$ & $5.32(2.15)$ \\
HAK & $4.51(2.43)$ & $4.39(2.34)$ & $4.45(2.42)$ \\
HTL & $4.97(2.27)$ & $4.93(2.41)$ & $5.03(2.47)$ \\
Non technical subject & $4.37(2.40)$ & $4.25(2.37)$ & $4.39(2.47)$ \\
Technical subject & $5.37(2.12)$ & $5.17(2.22)$ & $5.33(2.19)$ \\
Female & $4.46(2.57)$ & $4.35(2.44)$ & $4.51(2.47)$ \\
Male & $5.02(2.17)$ & $4.85(2.28)$ & $4.98(2.34)$ \\
No 3D printing experience & $6.47(1.02)$ & $6.63(0.83)$ & $6.68(0.75)$ \\
3D printing experience & $4.44(2.37)$ & $4.22(2.34)$ & $4.38(2.43)$ \\
Total & $4.82(2.32)$ & $4.67(2.34)$ & $4.81(2.39)$ \\
\hline
\end{tabular}

We further compared our early adopters with the early majority using independent sample $T$ test and Chi square tests (Table 2). There are no significant group mean differences concerning age $(t=0.392, \rho$ value $=0.696)$, teaching experience $(t=0.270, \rho$ value $=0.787)$, gender (Chi square $=3.095, \rho$ value $<0.079$ ), subject taught $($ Chi square $=0.361, \rho$ value $=0.548)$, and $3 \mathrm{D}$ printing experience $($ Chi square $=0.118, \rho$ value $=0.731)$ between the two groups.

Table 2 Sample descriptive

\begin{tabular}{lll}
\hline & Early adopter & Early majority \\
\hline Age & & \\
M (SD) & $45.3(9.6)$ & $46.2(9.6)$ \\
Min./Max. & $26 / 64$ & $26 / 64$ \\
Teaching experience & & \\
M (SD) & $16.6(10.6)$ & $17.3(10.4)$ \\
Min./Max. & $1 / 38$ & $1 / 40$ \\
Gender & & \\
Male (\%) & $19(79.2)$ & $47(59.5)$ \\
Female (\%) & $5(20.8)$ & $32(40.5)$ \\
Subject taught & & $45(57)$ \\
Non technical (\%) & $12(50)$ & $34(43)$ \\
Technical (\%) & $12(50)$ & $14(17.7)$ \\
3D printing experience & & $65(82.3)$ \\
No (\%) & $5(20.8)$ & \\
Yes (\%) & $19(79.2)$ & $79(100)$ \\
Total & & \\
$n(\%)$ & $24(100)$ &
\end{tabular}


Table 3 Results of group comparisons

\begin{tabular}{lllr}
\hline & $\begin{array}{l}\text { Early adopter M } \\
(\mathrm{SD}) n=24\end{array}$ & $\begin{array}{l}\text { Early majority M } \\
(\mathrm{SD}) n=79\end{array}$ & $\begin{array}{l}\text { Significance tests } \\
t \text { value }(\rho \text { value })\end{array}$ \\
\hline Performance expectancy & $5.38(1.47)$ & $4.13(1.99)$ & $-3.321(0.002)$ \\
Effort expectancy & $5.75(1.12)$ & $5.05(1.64)$ & $-1.957(0.053)$ \\
Social influence & $4.22(1.72)$ & $3.82(1.96)$ & $-0.887(0.377)$ \\
Anxiety & $1.53(1.26)$ & $1.67(1.25)$ & $0.479(0.633)$ \\
Attitude toward using technology & $6.72(0.44)$ & $5.66(1.45)$ & $-5.672(0.000)$ \\
Facilitating conditions & $3.74(1.58)$ & $4.20(1.87)$ & $1.089(0.279)$ \\
\hline
\end{tabular}

Seven-point Likert-scale with levels ranging from $1=$ "strongly disagree" to 7 ="strongly agree"

In a next step, we controlled for mean differences between the early adopters and the early majority of respondents concerning the UTAUT constructs. To compare the two groups, we conducted independent sample $T$ test. The results of the comparison are summarized in Table 3. The results highlight that there are significant differences in the PE and ATUT between the two groups.

\subsection{Measurement}

We adapted the UTAUT scales from Venkatesh et al. (2003) with appropriate modifications to measure BI to use 3D printing, PE, EE, SI, ANX, ATUT, and FC. We took particular care to ensure that the final items were as close to the original form as possible. Individuals were asked to indicate their agreement or disagreement on seven-point Likertscales with levels ranging from (1) strongly disagree to (7) strongly agree. All items used are listed in Table 4. We tested the reliability of our measures by estimating the Cronbach's Alpha. All UTAUT constructs exceeded the cut-off value of 0.7, with the exception of the FC construct. Sumak and Sorgo (2016) reported similar problems with the FC construct. With the option "scale-if-item-deleted" the indicator FC3 was removed and the threshold was reached (Table 4).

\section{Results}

We estimated a multiple linear regression model including PE, EE, SI, ATUT, ANX, and FC. Further, we controlled for early adopter, gender, and age. Because of our study context, we also included a dummy variable for technical subject taught. Further, we controlled for previous experience with 3D printing technology in our regression model (see Table 5).

We calculated the variance inflation factors (VIF) for all predictor variables in order to check for potential multi-collinearity problems. All VIF coefficients were below 2.7, indicating that multi-collinearity is not an issue in our analysis (Hair et al. 2006).

The $R$-square and adj. $R$-square values are 0.614 and 0.568 respectively and indicate a satisfying model fit (Table 6). The results of the multiple linear regression analysis indicate that the coefficients of PE, ATUT, and FC are significantly positive. Therefore, teachers with higher scores on PE, ATUT, and FC have stronger BI to use 3D printing technology. In addition, the coefficient for ANX is significantly negative, meaning that teachers with higher scores on ANX have weaker BI to use 3D printing technology. The significant 
Table 4 Descriptive statistics

\begin{tabular}{|c|c|c|}
\hline Item & Statement & $\mathrm{M}(\mathrm{SD}) n=103$ \\
\hline \multicolumn{2}{|c|}{ Performance expectancy } & Cronbach's $\alpha 0.902$ \\
\hline PE1 & I would find 3D printing useful in my job & $5.12(1.967)$ \\
\hline PE2 & 3D printing enables me to accomplish tasks more quickly & $3.80(2.204)$ \\
\hline PE3 & $3 \mathrm{D}$ printing increases my productivity & $4.22(2.227)$ \\
\hline \multicolumn{2}{|c|}{ Effort expectancy } & Cronbach's $\alpha 0.941$ \\
\hline EE1 & $\begin{array}{l}\text { My interaction with 3D printing would be clear and understand- } \\
\text { able }\end{array}$ & $5.05(1.794)$ \\
\hline EE2 & It would be easy for me to become skillful at using $3 \mathrm{D}$ printing & $5.29(1.651)$ \\
\hline EE3 & I would find the $3 \mathrm{D}$ printing easy to use & $5.14(1.668)$ \\
\hline EE4 & Learning to operate $3 \mathrm{D}$ printing is easy for me & $5.36(1.700)$ \\
\hline \multicolumn{2}{|c|}{ Social influence } & Cronbach's $\alpha 0.829$ \\
\hline SI1 & $\begin{array}{l}\text { People who influence my behavior think that I should use 3D } \\
\text { printing }\end{array}$ & $3.43(2.253)$ \\
\hline $\mathrm{SI} 2$ & $\begin{array}{l}\text { People who are important to me think that I should use 3D print- } \\
\text { ing }\end{array}$ & $3.51(2.234)$ \\
\hline SI3 & $\begin{array}{l}\text { The principal of this school has been helpful in the use of 3D } \\
\text { printing }\end{array}$ & $3.05(2.238)$ \\
\hline SI4 & In general, the organization has supported the use of $3 \mathrm{D}$ printing & $5.00(2.246)$ \\
\hline \multicolumn{2}{|c|}{ Attitude toward using technology } & Cronbach's $\alpha 0.911$ \\
\hline ATUT1 & Using 3D printing is a good idea & $6.40(1.149)$ \\
\hline ATUT2 & $3 \mathrm{D}$ printing makes work more interesting & $5.65(1.806)$ \\
\hline ATUT3 & Working with $3 \mathrm{D}$ printing is fun & $5.89(1.464)$ \\
\hline ATUT4 & I like working with $3 \mathrm{D}$ printing & $5.54(1.699)$ \\
\hline \multicolumn{2}{|l|}{ Anxiety } & Cronbach's $\alpha 0.912$ \\
\hline ANX1 & I feel apprehensive about using 3D printing & $1.92(1.673)$ \\
\hline ANX2 & $\begin{array}{l}\text { It scares me to think I could lose a lot of information using } 3 \mathrm{D} \\
\text { printing by hitting a wrong button }\end{array}$ & $1.60(1.360)$ \\
\hline ANX3 & $\begin{array}{l}\text { I hesitate to use 3D printing for fear of making mistakes I cannot } \\
\text { correct }\end{array}$ & $1.55(1.289)$ \\
\hline ANX4 & $3 \mathrm{D}$ printing is somewhat imitating to me & $1.48(1.243)$ \\
\hline \multicolumn{2}{|c|}{ Facilitating conditions } & Cronbach's $\alpha 0.706$ \\
\hline FC1 & I have the resources necessary to use $3 \mathrm{D}$ printing & $4.10(2.292)$ \\
\hline $\mathrm{FC} 2$ & I have the knowledge necessary to use $3 \mathrm{D}$ printing & $3.63(2.063)$ \\
\hline FC3 & $3 \mathrm{D}$ printing is compatible with other system I use & (excluded) \\
\hline FC4 & $\begin{array}{l}\text { A specific person (or group) is available for assistance with } 3 \mathrm{D} \\
\text { printing difficulties }\end{array}$ & $4.45(2.423)$ \\
\hline \multicolumn{2}{|c|}{ Behavioral intention } & Cronbach's $\alpha 0.911$ \\
\hline BI1 & I intend to use 3D printing in the next 6 months & $4.82(2.321)$ \\
\hline $\mathrm{BI} 2$ & I predict I would use 3D printing in the next 6 months & $4.67(2.339)$ \\
\hline $\mathrm{BI} 3$ & I plan to use $3 \mathrm{D}$ printing in the next 6 months & $4.81(2.386)$ \\
\hline
\end{tabular}

coefficients indicate that H1, H4, and $\mathbf{H 5}$ are supported. Further, the BI to use 3D printing technology is also predicted significantly by external factors. The results confirm that a positive perception of FC leads to a stronger BI to use 3D printing $(\beta=0.462, \rho<0.05)$. Thus, hypothesis $\mathbf{H 6}$ is also supported. However, the coefficients of EE and SI are not significant. Therefore, we have to reject hypotheses $\mathbf{H 2}$ and $\mathbf{H 3}$ (Table 7). 
Table 5 Variables used in the regression model

\begin{tabular}{|c|c|c|}
\hline Item (source) & Statement & Type \\
\hline Early adopter & $\begin{array}{l}\text { Teachers participating in the } \\
\text { kick-off event. We assigned the } \\
\text { value } 1 \text { for participants and } 0 \text { for } \\
\text { non-participants }\end{array}$ & Dummy \\
\hline Gender & & Dichotomous \\
\hline Age & & Metric \\
\hline $3 \mathrm{D}$ printing experience & I have experience in $3 \mathrm{D}$ printing & Dichotomous \\
\hline Technical subject & $\begin{array}{l}\text { Teachers teaching technical sub- } \\
\text { jects We assigned the value } 1 \text { for } \\
\text { teachers that teach technical sub- } \\
\text { jects and } 0 \text { for teachers that teach } \\
\text { academic or business subjects }\end{array}$ & Dummy \\
\hline Performance expectancy (Venkatesh et al. 2003) & See Table 4 & \\
\hline Effort expectancy (Venkatesh et al. 2003) & See Table 4 & \\
\hline Social influence (Venkatesh et al. 2003) & See Table 4 & \\
\hline $\begin{array}{l}\text { Attitude toward using technology (Venkatesh et al. } \\
\text { 2003) }\end{array}$ & See Table 4 & \\
\hline Anxiety (Venkatesh et al. 2003) & See Table 4 & \\
\hline Facilitating conditions (Venkatesh et al. 2003) & See Table 4 & \\
\hline Behavioral intention (Venkatesh et al. 2003) & See Table 4 & \\
\hline
\end{tabular}

Table 6 Results of the multiple linear regression analysis

\begin{tabular}{lccrc}
\hline Variables & Estimate & SE & $t$ value & Sig. \\
\hline Constant & 5.988 & 0.938 & 6.381 & 0.000 \\
Early adopter & $1.531^{* *}$ & 0.402 & 3.811 & 0.000 \\
Gender & 0.097 & 0.347 & 0.279 & 0.781 \\
Age & -0.008 & 0.016 & -0.505 & 0.615 \\
3D printing experience & $-1.087^{*}$ & 0.483 & -2.251 & 0.027 \\
Technical subject & -0.607 & 0.377 & -1.610 & 0.111 \\
Performance expectancy & $0.555^{*}$ & 0.241 & 2.306 & 0.023 \\
Effort expectancy & -0.248 & 0.205 & -1.212 & 0.229 \\
Social influence & 0.043 & 0.211 & 0.204 & 0.838 \\
Attitude toward using technology & $0.625^{*}$ & 0.213 & 2.934 & 0.004 \\
Anxiety & $-0.451^{*}$ & 0.162 & -2.787 & 0.006 \\
Facilitating conditions & $0.478^{*}$ & 0.211 & 2.263 & 0.026 \\
R-square & 0.614 & & & \\
Adj. R-square & 0.568 & & & \\
F-statistic with 6 and 91 df & $11.908^{* *}$ & & & \\
\hline
\end{tabular}

Multiple linear regression model with dependent variable: behavioral intention to use 3D printing; Level of significance: $* \rho<0.05$, $* * \rho<0.01$ 
Table 7 Summary of hypotheses tested

\begin{tabular}{ll}
\hline Hypothesis & Result \\
\hline H1 Teachers with high levels of performance expectancy are more likely to have a stronger & Supported \\
intention to use 3D printing technology & \\
H2 Teachers with high levels of effort expectancy are more likely to have a stronger inten- & Not supported \\
tion to use 3D printing technology & \\
H3 Teachers with high levels of social influence are more likely to have a stronger intention & Not supported \\
to use 3D printing technology & \\
H4 Teachers with high levels of anxiety are less likely to have a stronger intention to use & Supported \\
3D printing technology & \\
H5 Teachers with a positive attitude towards using 3D printing technology are more likely & Supported \\
to have a stronger intention to use 3D printing technology & Supported \\
H6 Teachers who perceive facilitating conditions positively are more likely to have a & \\
stronger intention to use 3D printing technology & \\
\hline
\end{tabular}

With respect to the control variables, we found that early adopters have a significantly stronger BI to use 3D printing technology $(\rho<0.01)$. Further, previous experience with 3D printing has a significantly negative impact on teacher BI to use 3D printing $(\rho<0.05)$. The coefficients for gender, age, and subject taught are not significant.

\section{Discussion and conclusions}

The present study investigates the impact of performance expectancy, effort expectancy, social influence, attitude toward using technology, anxiety, and facilitating conditions on teachers' behavioral intention to use novel technology. Thus, it extends the empirically validated UTAUT framework with additional variables. Further, we applied the framework to investigate novel technology adoption. We also contribute to a better knowledge about the adoption of novel technology in the context of high school teachers. The main goal to contribute to a better understanding of teacher acceptance of novel technology and their intention to use it was thus achieved. The findings provide evidence that there is a strong intention among teachers to use novel technology. Further, we demonstrate which personal and environment-related factors affect novel technology adoption.

We found empirical support for four of our six research hypotheses. The results show that performance expectancy (H1), anxiety (H4), attitude toward using technology (H5), and facilitating conditions (H6) were significant predictors of teachers' behavioral intention to use novel technology. In line with previous research (e.g. Sumak and Sorgo 2016), performance expectancy significantly affects individual's intention to use novel technology. This finding implies that the decision regarding the adoption of $3 \mathrm{D}$ printing is highly influenced by the perceived advantages that the novel technology provides. Anxiety is the second significant predictor that affects behavioral intention to use novel technology. This result indicates that the individual intention to use 3D printing is negatively influenced by the perceived possibility of either making uncorrectable mistakes or technology apprehension. Attitude towards technology is the third predictor that has a significant positive impact on teacher's behavioral intention to use novel technology. This result implies that individuals who perceive 3D printing as an interesting technology that is fun to work with have stronger intention to adopt the technology. Further, consistent with previous research (e.g. Macedo 2017), facilitating 
conditions have a significantly positive effect on the behavioral intention to use novel technology. This finding implies that individuals who perceive their environment as supporting have stronger intention to adopt novel technology. In other words, teachers who are equipped with the necessary resources, knowledge, and support are more likely to use $3 \mathrm{D}$ printing. This finding is in line with previous research that demonstrates that introducing novel technology into classrooms is not just a financial or technical issue. The successful introduction of novel technology needs to be accompanied with appropriate tailored content, pedagogy, and support (Mishra and Koehler 2006). Further, all actions need to be assessed and implemented carefully in order to secure successful adoption (Klauss 2000). Otherwise, the novel technology might be underutilized and end up as a dust collector (Mueller et al. 2008).

At least partly contrary to previous research, we found no empirical support that effort expectancy (H2) and social influence (H3) have a significant impact on the behavioral intention to adopt novel technology. This finding indicates that teachers' intention to adopt novel technology is not affected by the technology's perceived ease of use. Thus, in our context effort expectancy does not play a crucial role in the adoption decision. This finding is in line with Sumak and Sorgo (2016) who reported that effort expectancy is not a significant predictor on teachers' intention to use interactive whiteboards. The results further indicate that teachers are indifferent to important other peoples' thoughts and opinions about 3D printing. Thus, social influence is not a significant predictor of behavioral intention. This result is consistent with Kabra et al. (2017), for example, who did not find significant effects of social influence on the behavioral intention to use information technology.

What is particularly interesting is that previous experience with 3D printing has a significant negative impact on teachers' adoption intention. This finding indicates a negative previous experience. One possible explanation could be that the usage of the technology did not meet teachers' expectations. As a result, teachers have a negative perception of the technology. As mentioned earlier, 3D printing has raised divergent expectations about its future impact. It may be that the hype surrounding the technology has catalyzed expectations to a certain high level that the technology in its current development was not able to meet. In addition, especially early versions of consumer-grade 3D printers have been advertised as plug-and-play systems. However, operating these printers still required at least basic knowledge of materials, printing temperature, and design. Unsurprisingly, the dummy variable for early adopters is significant.

\subsection{Implications}

The findings of our study make a significant contribution to the literature on novel technology adoption. We applied the UTAUT model to determine the predictors of novel technology adoption. Previous research has primarily focused on technologies with low degrees of novelty. Few studies have investigated novel technology adoption. Thus, knowledge on novel technology adoption has remained insufficient. We contribute to a better understanding of the individual novel technology adoption processes.

Further, we extended the UTAUT model by integrating anxiety and attitude toward using technology into our analysis. To the best of our knowledge, this is the first study that investigates the role of anxiety and attitude toward using technology in novel technology adoption processes. In previous research the role of anxiety and attitude towards using technology was vague. Our research contributes to more clarity by indicating that anxiety and attitude towards using technology are significant predictors in the individual adoption 
processes. Thus, future studies on novel technology adoption should integrate anxiety and attitude towards using technology for further clarification.

The results of our research further provide valuable insights into crucial factors that influence the behavioral intention of teachers to adopt novel technology. Our findings can be used as a practical guideline to successfully introduce novel technologies among teachers. The knowledge of critical success factors of novel technology adoption enables policy makers and principals to provide tailor-made offers that facilitate adoption rates. For instance, policy makers are asked to integrate novel technologies stronger in high school curricula. In particular, that means to intensify the knowledge about when and how to use novel technology. Nonetheless, in order to truly understand and master novel technology, students have to use it in class actively. Thus, there is a need for proper 3D printing equipment (hardware and software) in schools. Policy makers can support the acquisition, for instance, by dedicating budgets to create 3D printing labs in schools.

Principals should be aware that their schools could attain benefits if they are among the early adopters of novel technology. For instance, the early adoption can enable them to create novel and more attractive learning environments quicker than others. Thus, these schools are also regularly viewed as more sophisticated and advanced. Schools might be able to capitalize on this positive image by attracting more students.

Finally, our study provides valuable insights for 3D printer manufacturers aiming to target the educational market. The findings indicate that (1) teachers need to be further convinced of the potentials of 3D printing, (2) manufacturers should be more realistic about the communicated performance and ease of use in order to prevent false and unattainable expectations, and (3) additional training and support is needed in order to secure that the technology is used to its full potential and does not end up another underutilized classroom tool. Thus, these services should be integral parts of the business model.

\subsection{Limitations and future research}

We are fully aware that our study has certain limitations. However, these limitations provide opportunities for future research. First, with 103 respondents the sample in our study is sufficient. Compared to the overall number of teachers in the region (2.876) the number of respondents corresponds to $3.58 \%$ of the entire population. Thus, we believe the number suffices for a first analysis of teacher's adoption of novel technology. Data from the 2016 annual report of the Austrian Federal Ministry of Education, Science and Research show that there is no significant difference in the distribution of teachers and school types between the surveyed region and Austria overall. In the Austrian high school education system there are more female teachers (57.8\%) than male teachers (42.2\%). This is particularly true for academic secondary schools (AHS) (63.8\% women) and secondary colleges of business administration (HAK) (65.8\% women). In higher federal technical colleges (HTL) men outnumber women (27.2\% women). In our sample HTL are overrepresented (29.1\% compared to $20.7 \%$ in Austria). However, we do have a self-selection bias. More men $(64.1 \%)$ chose to participate than women $(35.9 \%)$. Due to this limitation, there is a need for larger scale studies to confirm our results.

Second, we applied the UTAUT model as our theoretical framework. We extended the model by integrating anxiety and attitude toward using technology. Future research is needed to confirm our results. Further, we are aware that there are other determinants that could be applied to investigate novel technology adoption among teachers. Future research could build upon our extended UTAUT model and investigate the relevance of additional 
factors such as habit. Habit relates to the reflection of perceived results and prior experiences (Macedo 2017).

Third, due to the novelty of the technology and the low adoption rate, we were not able to test whether behavioral intention in our context leads to actual use. The high schools in our sample mostly do not have 3D printing technology yet. Thus, future research should be conducted to investigate whether the behavioral intention leads to actual use of novel technology.

Fourth, the study was conducted among high school teachers in an Austrian region. Thus, it is possible geographical and cultural factors affect teacher's behavioral intention to adopt the novel technology. Future research should investigate whether our results are applicable to different geographical and cultural contexts. Until then the generalizability of our results might be limited.

Acknowledgements Open access funding provided by University of Klagenfurt.

Open Access This article is distributed under the terms of the Creative Commons Attribution 4.0 International License (http://creativecommons.org/licenses/by/4.0/), which permits unrestricted use, distribution, and reproduction in any medium, provided you give appropriate credit to the original author(s) and the source, provide a link to the Creative Commons license, and indicate if changes were made.

\section{References}

Ajzen, I. (1991). The theory of planned behavior. Organizational Behavior and Human Decision Processes, 50(2), 179-211.

Albors, J., Hervas, J. L., \& Hidalgo, A. (2006). Analysing high technology diffusion and public transference programs: The case of the European Game Program. Journal of Technology Transfer, 31(6), 647-661.

Bandura, A. (1986). Social foundations of thought and action: A social cognitive theory. Englewood Cliffs: Prentice Hall.

Berman, B. (2012). 3-D printing: the new industrial revolution. Business Horizons, 55(2), 155-162.

Comin, D., Hobijn, B., \& Rovito, E. (2008). A new approach to measuring technology with an application to the shape of the diffusion curves. Journal of Technology Transfer, 33(2), 187-207.

Davis, F. D. (1989). Perceived usefulness, perceived ease of use, and user acceptance of information technology. MIS Quarterly, 13(3), 319-339.

Davis, F. D., Bagozzi, R. P., \& Warshaw, P. R. (1989). User acceptance of computer technology: A comparison of two theoretical models. Management Science, 35(8), 982-1002.

Despeisse, M., Baumers, M., Brown, P., Charnley, F., Ford, S. J., Garmulewicz, A., et al. (2017). Unlocking value for a circular economy through 3D printing: A research agenda. Technological Forecasting and Social Change, 115, 75-84.

Gartner, J., Maresch, D., \& Fink, M. (2015). The potential of additive manufacturing for technology entrepreneurship: An integrative technology assessment. Creativity and Innovation Management, 24(4), 585-600.

Hair, J. F., Black, W. C., Babin, B. J., Anderson, R. E., \& Tatham, R. L. (2006). Multivariate data analysis (6th ed.). Upper Saddle River: Pearson/Prentice Hall.

Holmström, J., Partanen, J., Tuomi, J., \& Walter, M. (2010). Rapid manufacturing in the spare parts supply chain. Alternative approaches to capacity deployment. Journal of Manufacturing Technology Management, 21(6), 687-697.

Holzmann, P., Breitenecker, R. J., \& Schwarz, E. J. (2015). Business models for disruptive technologiesFindings from the 3D printing industry. In 60th international council on small business (ICSB) world conference (pp. 6-9).

Holzmann, P., Breitenecker, R. J., Soomro, A. A., \& Schwarz, E. J. (2017). User entrepreneur business models in 3D printing. Journal of Manufacturing Technology Management, 28(1), 75-94.

Hoque, R., \& Sorwar, G. (2017). Understanding factors influencing the adoption of mHealth by the elderly: An extension of the UTAUT model. International Journal of Medical Informatics, 101, 75-84. 
Huang, S. H., Liu, P., Mokasdar, A., \& Hou, L. (2013). Additive manufacturing and its societal impact: A literature review. The International Journal of Advanced Manufacturing Technology, 67(5-8), 1191-1203.

Jiang, R., Kleer, R., \& Piller, F. T. (2017). Predicting the future of additive manufacturing: A Delphi study on economic and societal implications of 3D printing for 2030. Technological Forecasting and Social Change, 117, 84-97.

Kabra, G., Ramesh, A., Akhtar, P., \& Dash, M. K. (2017). Understanding behavioral intention to use information technology: Insights from humanitarian practitioners. Telematics and Informatics, 34, $1250-1261$.

Klauss, R. (2000). Technology transfer in education-Application to developing countries. Journal of Technology Transfer, 25(3), 277-287.

Kwak, K., Kim, W., \& Park, K. (2017). Complementary multiplatforms in the growing innovation ecosystem: Evidence from 3D printing technology. Technological Forecasting and Social Change. https://doi. org/10.1016/j.techfore.2017.06.022 (in press, corrected proof).

Macedo, I. A. (2017). Predicting the acceptance and use of information and communication technology by older adults: An empirical examination of the revised UTAUT2. Computers in Human Behavior, 75, 935-948.

Magsamen-Conrad, K., Upadhyaya, S., Joa, C. Y., \& Dowd, J. (2015). Bridging the divide: Using UTAUT to predict multigenerational tablet adoption practices. Computers in Human Behavior, 50, 186-196.

Meuter, M. L., Ostrom, A. L., Bitner, M. J., \& Roundtree, R. (2003). The influence of technology anxiety on consumer use and experiences with self-service technologies. Journal of Business Research, 56(11), 899-906.

Mishra, P., \& Koehler, M. J. (2006). Technological pedagogical content knowledge: A framework for teacher knowledge. The Teachers College Record, 108(6), 1017-1054.

Moore, G. C., \& Benbasat, I. (1991). Development of an instrument to measure the perceptions of adopting an information technology innovation. Information Systems Research, 2(3), 192-222.

Mueller, J., Wood, E., Willoughby, T., Ross, C., \& Specht, J. (2008). Identifying discriminating variables between teachers who fully integrate computers and teachers with limited integration. Computers \& Education, 48(2), 250-267.

Oh, J., \& Yoon, S. (2014). Predicting the use of online information services based on a modified UTAUT model. Behaviour \& Information Technology, 33(7), 716-729.

Ozusaglam, S., Robin, S., \& Wong, C. Y. (2017). Early and late adopters of ISO 14001-type standards: Revisting the role of firm characteristics and capabilities. Journal of Technology Transfer. https://doi. org/10.1007/s10961-017-9560-5.

Rayna, T., \& Striukova, L. (2016). From rapid prototyping to home fabrication: How 3D printing is changing business model innovation. Technological Forecasting and Social Change, 102, 214-224.

Redmann, D. H., \& Kotrlik, J. W. (2004). Analysis of technology integration in the teaching-learning process in selected career and technical education programs. Journal of Vocational Education Research, 29(1), 3-25.

Schniederjans, D. G. (2017). Adoption of 3D-printing technologies in manufacturing: A survey analysis. International Journal of Production Economics, 183, 287-298.

Sheppard, B. H., Hartwick, J., \& Warshaw, P. R. (1988). The theory of reasoned action: A meta-analysis of past research with recommendations for modifications and future research. Journal of Consumer Research, 15(3), 325-343.

Sumak, B., \& Sorgo, A. (2016). The acceptance and use of interactive whiteboards among teachers: Differences in UTAUT determinants between pre- and post-adopters. Computers in Human Behavior, 64, $602-620$.

Taiwo, A. A., \& Downe, A. G. (2013). The theory of user acceptance and use of technology (UTAUT): A meta-analytic review of empirical findings. Journal of Theoretical and Applied Information Technology, 49(1), 48-58.

Taylor, S., \& Todd, P. (1995). Assessing IT usage: The role of prior experience. Management Information Systems Quarterly, 19(4), 561-570.

Thompson, R. L., Higgins, C. A., \& Howell, J. M. (1991). Personal computing: Toward a conceptual model of utilization. MIS Quarterly, 15(1), 124-143.

Venkatesh, V. (2000). Determinants of perceived ease of use: Integrating perceived behavioral control, computer anxiety and enjoyment into the technology acceptance model. Information Systems Research, 11(4), 342-365.

Venkatesh, V., Morris, M. G., Davis, G. B., \& Davis, F. D. (2003). User acceptance of information technology: Toward a unified view. MIS Quarterly, 27(3), 425-478. 
Venkatesh, V., Thong, J. Y. L., \& Xu, X. (2012). Consumer acceptance and use of information technology: Extending the unified theory of acceptance and use of technology. MIS Quarterly, 36(1), 157-178.

Verdegem, P., \& De Marez, L. (2011). Rethinking determinants of ICT acceptance: Towards an integrated and comprehensive overview. Technovation, 31, 411-423.

Weller, C., Kleer, R., \& Piller, F. T. (2015). Economic implications of 3D printing: Market structure models in light of additive manufacturing revisited. International Journal of Production Economics, 164, 43-56.

Wohlers, T., \& Caffrey, T. (2014). Wohlers report 2014. 3D printing and additive manufacturing state of the industry. Annual worldwide progress report. Fort Collins, CO: Wohlers Associates.

Xu, G., Wu, Y., Minshall, T., \& Zhou, Y. (2017). Exploring innovation ecosystems across science, technology, and business: A case of 3D printing in China. Technological Forecasting and Social Change. https ://doi.org/10.1016/j.techfore.2017.06.030 (in press, corrected proof).

Yeh, C.-C., \& Chen, Y.-F. (2018). Critical success factors for adoption of 3D printing. Technological Forecasting and Social Change, 132, 209-216.

Yi, M. Y., Jackson, J. D., Park, J. S., \& Probst, J. C. (2006). Understanding information technology acceptance by individual professionals: Toward an integrative view. Information Management, 43, 350-363. 